\title{
A FILOSOFIA DA EDUCAÇÃO DE RICHARD RORTY: EPISTEMOLOGIA, CONVERSAÇÃO, REDESCRIÇÕES, NARRATIVAS E AS FUNÇÕES DA EDUCAÇÃO
}

\author{
Heraldo Aparecido Silva*
}

\begin{abstract}
RESUMO
Este trabalho tem por objetivo analisar alguns aspectos da filosofia da educação de Richard Rorty. Nessa abordagem privilegiaremos os antecedentes teóricos dos distintos e complementares processos educacionais de socialização e individualização: a crítica ao paradigma epistemológico, a proposta de um novo paradigma conversacional ou educacional, o método filosófico da redescrição e o uso de narrativas como elemento formativo. Ressaltamos que nossa análise é uma tentativa de determinar os limites e os pontos de intersecção entre os dois processos educacionais, articulados com a possibilidade do uso de narrativas como elemento de formação. As considerações finais indicam que tal proposta neopragmatista é um incentivo em prol da manutenção de hábitos de ação que resultam em uma solidariedade humana criada por meio do aumento de nossa sensibilidade aos pormenores específicos da dor e humilhação que padecem outros seres humanos desconhecidos.
\end{abstract}

Palavras-chave: Pragmatismo. Epistemologia. Educacão. Narrativas. Rorty.

\begin{abstract}
The objective of this study is to examine some aspects of Richard Rorty's philosophy of education. In this approach we will favor the philosophical background of distinctive and complementary educational processes of socialization and individualization: the critical to epistemological paradigm, the proposition of a new educational or conversational paradigm, the philosophical method of redescription and the use of narratives as formative element. We highlight that our analysis is an endeavour to determine the limits and the intercession points between two educational
\end{abstract}

* Doutorado em Filosofia pela Universidade Federal de São Carlos (UFSCAR). Professor Adjunto no Centro de Ciências da Educação da Universidade Federal do Piauí (UFPI). E-mail: heraldokf@yahoo.com.br 
processes, articulated with the possible use of the narratives as formative element. Final considerations indicate that this neopragmatist proposal is an incentive in favour of maintenance of habit of action which resulted in a human solidarity is created by increasing our sensibility to the specific details of the pain and humiliation of other unfamiliar human beings.

Keywords: Pragmatism. Epistemology. Education. Narratives. Rorty.

\section{Pragmatismo, epistemologia e conversação}

O termo pragmatismo designa a corrente filosófica surgida nos Estados Unidos da América, entre meados do século XIX e as duas décadas iniciais do século XX. Em linhas gerais, o pragmatismo se notabilizou como uma filosofia da ação avessa à mera contemplação praticada pela filosofia tradicional que, em seus estudos, sempre contemplou questões práticas, de natureza política, social e educacional. De maneira geral, a origem do pragmatismo é atribuída a Charles Sanders Peirce (1839-1914), William James (1842-1910) e John Dewey (1859-1952), os chamados pragmatistas clássicos. Embora Peirce não tenha escrito especificamente sobre a educação, suas ideias têm reconhecidamente "aplicações educacionais imediatas", enquanto que James e, principalmente, Dewey legaram importantes escritos para a pesquisa educacional (GARRISON; NEIMAN, 2003, p. 22-30).

Nenhum dos pragmatistas clássicos chegou a conhecer o neopragmatismo, a versão contemporânea do pragmatismo na acepção de Richard Rorty (1931-2007), um dos principais filósofos norte-americanos da atualidade e continuador da tradição pragmatista. Rorty (2000a) sustenta que, ao contrário do que acredita a maior parte da tradição filosófica, a política e a filosofia dependem da educação e não o inverso. Para ele a educação é constituída por dois processos distintos e complementares: a socialização e a individualização. A dificuldade reside em determinar onde termina um processo e começa outro.

O pragmatismo, segundo Rorty (1991), é uma filosofia da esperança e da solidariedade e não do desespero. Consequentemente, a 
filosofia da educação que extraímos de seus escritos, configura um esforço no sentido de tentar determinar os limites e os pontos de intersecção entre os dois processos educacionais, articulados com a possibilidade do uso de narrativas como elemento de formação. Tal medida culmina numa tentativa de incentivo à manutenção de hábitos de ação que resultassem numa solidariedade humana criada por meio do aumento de nossa sensibilidade aos pormenores específicos da dor e humilhação que padecem outros seres humanos.

Não obstante, é preciso mencionar que tais ideias concernentes à educação constituem a culminância de um projeto iniciado há mais de trinta anos, quando o neopragmatista faz a antirrepresentacionista da Filosofia e propõe o abandono do paradigma epistemológico em prol do paradigma educacional, também referido como uma atitude filosófica conversacional. Rorty (1979, p. 10) critica a noção de conhecimento como representação ao "colocar as noções de mente, conhecimento e filosofia numa perspectiva histórica". Para ele, a filosofia do sujeito de Descartes é o ponto de partida para um projeto, posteriormente continuado de diferentes maneiras por Locke, Leibniz, Hume e Kant, que visa tornar a epistemologia a área central da filosofia e, com isso, fazer da mesma uma atividade privilegiada cujo objetivo seria não a busca da sabedoria e sim a busca da verdade que, por sua vez, permitiria fundamentar e legitimar as demais áreas do conhecimento (como a ciência, a literatura, a política, a arte, a religião, a educação, a moral etc.) ou, pelo contrário, fragilizar as mesmas através da não ratificação de suas asserções sobre o conhecimento.

Nessa perspectiva, a tradição epistemológica cartesiano-kantiana pode ser descrita como uma tentativa de busca por fundamentos do conhecimento. Então, para livrar-se do domínio que esta imagem exerce sobre o nosso pensamento, Rorty ataca a ideia de centralidade atribuída à epistemologia em relação à filosofia. Para tanto, ele sustenta que se concebermos "o conhecimento antes como uma questão de conversação e prática social do que uma tentativa de espelhar a natureza”, provavelmente não seremos tentados a imaginar "uma metaprática que será a crítica de todas as formas possíveis de prática social" e, consequentemente, a partir dessa perspectiva holística, onde a justificação (ou a não justificação) de uma crença ocorre mediante relações com outras crenças, será produzida 
"uma concepção de filosofia que nada tem a ver com a busca de certeza" (RORTY, 1979, p. 171).

Rorty defende que a lacuna deixada pela epistemologia não necessita ser preenchida por qualquer outra disciplina com propósitos fundacionistas similares, porque o "desejo por uma teoria do conhecimento é um desejo de limitação" (RORTY, 1979, p. 315). Esta limitação pode ser constatada no modo como a epistemologia, ao eleger o método objetivo científico, faz com que as demais áreas da cultura tenham que se conformar à ciência, restringindo-as; ou seja, para que suas investigações e contribuições sejam consideradas seriamente, elas devem aproximar-se o máximo possível do modelo de investigação científico.

Rorty crê, então, que devemos renunciar ao desejo de confrontação e restrição em prol do aprimoramento da conversação entre as várias áreas da cultura. Para tanto, temos como alternativa ao método científico, o método de interpretação (subjetivista) da hermenêutica. Ele afirma que aproximadamente a diferença entre a epistemologia e a hermenêutica pode ser traçada, respectivamente, a partir da distinção entre o estudo do familiar e o estudo do não familiar. Tal distinção, numa acepção genérica, encerra uma denominação abrangente o suficiente para abarcar outras oposições tais como: a distinção entre o literal e o metafórico, o necessário e o contingente, a teoria e a narrativa. Por conseguinte, pensar dessa maneira implica em ver a si próprio, na condição de filósofo, como um "auxiliar do poeta e não do físico" (RORTY, 1979, p. 8).

Assim, ao repudiar a restrita e hierarquizada noção de conhecimento em prol da conversação livre e aberta, Rorty sustenta que do "ponto de vista educacional, em oposição ao epistemológico e tecnológico, o modo como as coisas são ditas é mais importante do que a posse de verdades" (RORTY, 1979, p. 359). Ele continua:

Uma vez que 'educação' soa um pouco vazio demais, e Bildung um pouco estrangeiro demais, usarei 'edificação' para significar este projeto de encontrar novos, melhores, mais interessantes e mais fecundos modos de falar. A tentativa de edificar (a nós mesmos ou a outros) pode consistir na atividade hermenêutica de fazer conexões 
entre nossa própria cultura e alguma cultura exótica ou período histórico, ou entre nossa própria disciplina e outra disciplina que pareça perseguir objetivos incomensuráveis num vocabulário incomensurável. Mas pode, ao invés disso, consistir na atividade 'poética' de inventar novos objetivos, novas palavras ou novas disciplinas, seguida, por assim dizer, pelo inverso da hermenêutica: a tentativa de reinterpretar nosso ambiente familiar nos termos nãofamiliares de nossas novas invenções. Em qualquer caso, a atividade é (apesar da relação etmológica entre as duas palavras) edificante sem ser construtiva - pelo menos se 'construtivo' significa o tipo de cooperação na realização de programas de pesquisa que tem lugar no discurso normal. Pois o discurso edificante é suposto ser anormal, tirar-nos para fora de nossos velhos eus pelo poder da estranheza, para ajudar-nos a nos tornarmos novos seres (RORTY, 1979, p. 360).

O contraste entre a tendência epistemológica e a hermenêutica é ilustrado por meio do dístico filósofos sistemáticos versus filósofos edificantes. Os sistemáticos, como Descartes, Kant, Husserl e Russell, são "construtivos e oferecem argumentos" na tentativa de atingir a verdade (um relato genuíno da realidade e do conhecimento humano), um benefício que sirva indistintamente para todas as gerações através dos tempos e lugares; eles "constroem para a eternidade". Os edificantes como Wittgenstein, Heidegger e Dewey são "reativos e oferecem sátiras, paródias e aforismos" sem a pretensão de desvendar a verdade, mas apenas propor questões e ideias inéditas, muitas vezes expressas em vocabulários novos, o tempo suficiente para manter o interesse por coisas que "ainda não podem ser explicadas" ou que "são descritas insuficientemente". Como tais coisas (ideias, crenças e linguagens) podem vir a ser promissoras para alguns grupos (sem serem prejudiciais a outros) se não forem abandonadas, os edificantes "destroem pela causa de sua própria geração" (RORTY, 1979, p. 369-370). Tais ideias de destruição de antigas convenções e de proposição de alternativas, geralmente sob a forma de narrativas em prol do aprimoramento moral das novas gerações, sãos retomadas nos textos rortyanos específicos sobre a educação. 


\section{Redescrições, narrativas e solidariedade}

Para Rorty, assim como veremos posteriormente com relação aos processos de socialização e individualização, o papel a ser desempenhado pela filosofia é tão somente o de nos auxiliar a excluir as ideias retrógradas e descrever ou redescrever as ideias novas de modo a torná-las mais interessantes. O procedimento ou método filosófico da redescrição é qualificado nos seguintes termos:

O método consiste em redescrever muitas e muitas coisas de novas maneiras, até se criar um padrão de comportamento lingüístico, que criará na geração vindoura a tentação de adotá-lo, levando-a, dessa forma, a procurar formas novas e apropriadas de comportamento não lingüístico, por exemplo, a adoção de novos equipamentos científicos ou de novas instituições sociais. Este tipo de filosofia não trabalha peça por peça, analisando conceito após conceito, ou testando teses após teses. Em vez disso trabalha de forma holística e pragmática. Diz coisas como 'tente pensar nisto desta maneira' ou, mais especificamente, 'tente ignorar as aparentemente fúteis questões tradicionais, substituindo-as pelas seguintes questões novas e possivelmente interessantes'. Não pretende ter um candidato melhor para fazer as mesmas velhas coisas que fazíamos quando falávamos à moda antiga. Em vez disso sugere que paremos de fazer essas coisas e façamos algo diferente. Mas não argumenta em prol desta idéia com base em critérios prévios, comuns ao jogo de linguagem antigo e ao novo. Simplesmente porque na medida em que a linguagem é realmente nova, não haverá tais critérios (RORTY, 1989, p. 9).

A proposta rortyana defende que a principal ferramenta para a mudança cultural não é argumentar bem, mas falar de forma alternativa. Em tal concepção neopragmatista, não existe qualquer instância a-histórica, universal e absoluta que possa servir de ponto neutro a fim de julgar todas as culturas, visto que as pessoas e as culturas são consideradas como "vocabulários corporificados" (RORTY, 1989, p. 80). Deste modo, é a partir da modificação das práticas linguísticas e, consequentemente, de outras práticas sociais que novos tipos de seres humanos são produzidos. 
Nessa perspectiva, a relevância das narrativas neste processo educativo pode ser verificada por meio da sugestão de Rorty (1998) para quem a leitura de livros como o Novo Testamento e o Manifesto Comunista deveria ser encorajada por pais e professores, porque o conhecimento de tais narrativas e a posterior reação a ela contribuiriam para que as próximas gerações fossem moralmente melhores. Em geral, esta seria a esperança rortyana de que os jovens das próximas gerações, ao elaborarem suas próprias narrativas (sob a forma de romances, filmes, leis, instituições etc.), lembrem-se de ampliar o raio de ação do termo "nós", por mais estranho ou louco que tal descrição - ou redescrição - possa parecer para muitos de seus contemporâneos. Rorty escreve:

Devemos educar nossos filhos para que considerem insuportável o fato de nós, leitores do "Frankfurter Allgemeine Zeitung", sentado atrás de mesas e computadores, ganharmos dez vezes mais do que aqueles que sujam as mãos limpando lavabos e cem vezes mais do que aqueles que fabricam nossos computadores do Terceiro Mundo. Devemos nos certificar de que eles tenham consciência de que os países pioneiros na industrialização possuem uma riqueza cem vezes maior do que aqueles que ainda não se industrializaram. Os nossos filhos têm de aprender, desde cedo, a enxergar as desigualdades de suas fortunas e aquelas de outras crianças não como a 'Vontade de Deus', nem como 'o preço necessário da eficiência econômica', mas como uma tragédia evitável. Eles devem começar a pensar, o mais cedo possível, sobre como modificar o mundo, de modo a fazer com que ninguém passe fome enquanto outros se empanturram.

As crianças precisam ler a mensagem de fraternidade humana de Cristo em conjunto com o relato de Marx e Engels sobre como o capitalismo industrial e o mercado livre - indispensáveis como são hoje - tornaram muito difícil instituir essa fraternidade. Elas precisam ver suas vidas como esforços no sentido de realizar a nossa potencialidade moral, inerente a nossa capacidade de comunicar as nossas necessidades e esperanças. Elas devem ouvir histórias sobre as congregações cristãs que se reuniam nas catacumbas e sobre os comícios operários nas praças de metrópoles. De fato, ambos cumpriram papéis igualmente importantes no longo processo de realização dessas potencialidades (RORTY, 1998, p. 7). 
Em outras palavras, Rorty espera que possamos transformar partes do mundo, redescrevendo-o. Esta ideia prescinde do pressuposto universalista que sustenta a existência de uma essência humana comum em todos os seres humanos e, em contrapartida, investe em dois atributos comuns à humanidade: a humilhação e a narrativa. A humilhação é compreendida como a ideia de que todos são passíveis de sofrer um "tipo especial de dor", por meio do "desmantelamento forçado das estruturas particulares de linguagem e crença nas quais foram socializados (ou que se orgulham de ter formado por si próprios)" (RORTY, 1989, p. 177178). A narrativa, por sua vez, é configurada como a capacidade de contar histórias sobre sofrimentos ou triunfos passados e também sobre cenários alternativos, preferíveis aos atuais (RORTY, 1989, p. 182).

$\mathrm{Na}$ acepção rortyana, a fim de compreender ou justificar uma ação genocida, tanto as vítimas quanto os algozes podem até tentar inutilmente negar a humanidade uns dos outros; mas ninguém pode negar que se algo de ruim acontece com uma pessoa 'estranha' do outro lado do mundo o mesmo pode acontecer com qualquer um de nós. Assim, devemos nos importar com pessoas desconhecidas e contar a sua dramática história. Para convencer outras pessoas a ajudar indivíduos diferentes (no que tange ao país, raça, costumes, religião etc.) podemos concluir nosso relato com algo do tipo: 'devemos nos importar com ela porque isso poderia ter acontecido com um amigo seu'; ou ainda 'ela poderia ser sua filha'. Neste sentido, a solidariedade que apela para o individualismo das pessoas faz mais pela comunidade do que qualquer tentativa de justificação universalista (RORTY, 1989, p. 192-193).

Em outras palavras, Rorty espera que os filósofos sejam não auxiliares do físico, que supostamente descobre a representação correta de como o mundo é em si mesmo, mas do poeta que cria linguagens novas e consequentemente identidades morais e mundos novos. É por essa razão que Rorty, até o final de seus dias, optou por escrever cada vez menos sobre temas técnicos da filosofia para, em contrapartida, escrever cada vez mais sobre temas de interesse geral onde predominam sugestões sobre os usos da filosofia em prol da democracia e da liberdade. Esta opção resulta em textos nos quais existe a predominância de narrativas dramáticas ou inspiradoras que conectam "o presente e o passado, por um lado, e a utopias futuras, por 
outro" (RORTY, 1989, p. xvi). Assim, em vez da tradicional busca filosófica pela Verdade, temos a busca filosófica pela ampliação da liberdade: expansão esta, ilustrada por meio do diálogo livre e aberto sobre tópicos como política, cultura, ética e sociedade (RORTY, 2007, p. 42-130).

A realização desses encontros etnocêntricos (imediatos ou imaginários) entre pessoas de uma mesma cultura ou de culturas diferentes é o que permite a ampliação de nossa imaginação e consequentemente a ação do solidarismo e a mudança de antigas práticas linguísticas por outras: uma medida que, em longo prazo, resulta inclusive na alteração manutenção, aperfeiçoamento, extinção ou invenção - de hábitos, práticas sociais e instituições sociais e políticas.

\section{Educação como socialização e como individualização}

Rorty sustenta ser alguém que, da mesma maneira que duvida da importância da filosofia para a política, também tem dúvidas a respeito da relevância da filosofia para a educação. Esta declaração parece pôr em xeque a própria ideia de uma filosofia da educação inspiradas por motivos neopragmatistas rortyanos. Todavia, ao considerar o contexto em que tais palavras foram escritas, evitamos tal equívoco acerca de suas ideias relativas à educação. Nessa perspectiva, o neopragmatista justifica a sua posição:

A política - ou pelo menos o tipo de política no qual eu me interesso em participar - é o empreendimento de desenvolver instituições que protegerão o fraco contra o forte. A educação me parece dois empreendimentos razoavelmente distintos: a educação básica é principalmente uma questão de socialização, de tentar inculcar um sentido de cidadania, e a educação superior é principalmente uma questão de individualização, de tentar despertar a imaginação do indivíduo na esperança de que ele ser torne capaz de recriar a si mesmo. Eu não estou certo de que a filosofia possa fazer muito por qualquer desses empreendimentos (RORTY, 1997, p. 59).

Rorty retoma a linha de pensamento comum aos seus escritos anteriores, particularmente, nos livros Philosophy and the mirror of nature 
(1979) e Contingency, irony and solidarity (1989). Para Rorty, se a filosofia tiver alguma função social, esta se assemelha a uma tarefa terapêutica no sentido de auxiliar as pessoas a se livrarem dos pensamentos filosóficos retrógrados e a romper a crosta social. Assim, se no que no tange às questões políticas e educacionais, o principal instrumento para romper a crosta das convenções sociais é a "sugestão de alternativas", então, o que a filosofia pode fazer de melhor, para o avanço tanto da política quanto da educação, é "desenvolver uma retórica convincente para a apresentação dessas novas sugestões - tornando-as um pouco mais palatáveis" (RORTY, 1997, p. 60). A partir dessa percepção rortyana, é possível compreender que se alguma coisa pode ser feita pela política e, particularmente, pela educação, não serão as reflexões filosóficas e tampouco os intermináveis embates teóricos filosóficos os agentes para a consecução deste ato. Tanto no caso da política quanto no da educação, quando se trata de tomar decisões, buscar soluções para problemas específicos, ou mudar uma dada situação, não devemos superestimar a relevância da filosofia, pois em ambos os casos, em última análise, tudo isto é definido no processo das lutas explícitas ou implícitas pelo poder. Assim, no contexto educacional, o fator determinante não reside no campo filosófico, mas no âmbito das disputas travadas e decisões tomadas nas associações, federações e conselhos de educação. Desta maneira, a filosofia fica restringida a, no máximo, contribuir para tornar mais interessante um ou outro, dentre os discursos opositores.

A respeito da educação, Rorty (1997) concorda com Arcilla (1997), visto que ambos consideram que ela se encarrega antes de tudo, de garantir que o conhecimento seja transferido de geração para geração. Entretanto, a respeito de como ocorre o compartilhamento do conhecimento, no ensino básico (equivalente ao ensino fundamental e ao ensino médio) e no ensino superior (graduação e pós-graduação), Rorty (1997) responde com as noções distintas e complementares de socialização e individualização. Segundo ele, tanto os platônicos políticos conservadores de direita, partidários extremistas da socialização e da verdade, quanto os platônicos invertidos radicais de esquerda, partidários extremistas da individualização e da liberdade, "têm dificuldades em perceber que a educação não é um processo contínuo que vai dos 5 aos 22 anos"; e, por isso, eles "tendem a ignorar o fato de que a palavra educação abrange dois 
processos inteiramente diferentes e igualmente necessários - socialização e individualização" (RORTY, 1997, p. 72).

O processo de socialização abarca um espectro amplo de coisas a serem aprendidas nas escolas pelos jovens até, aproximadamente, a idade de dezenove anos - após a qual, haveria impaciência e resistência em relação referido processo; condição esta que, de certo modo, propiciaria o aumento da já vicejante receptividade dos estudantes para o início do processo autocrítico de individualização. Entre as coisas que fazem parte do aprendizado que visa integrar satisfatoriamente as pessoas na sociedade, temos, entre outros, os seguintes elementos: noções básicas de higiene e saúde, a distinção entre o comportamento na esfera particular e pública, o respeito ao próximo, a alfabetização fundamental (aprender a ler, pronunciar e escrever corretamente as palavras, além de interpretar textos), o aprendizado das primeiras operações matemáticas (adição, subtração, multiplicação e divisão), as noções acerca de hábitos e costumes difundidos incentivados na nossa cultura e, também, o aprendizado de determinadas leis, regras ou orientações que visam prevenir sobre ou inibir possíveis atos considerados ilícitos e danosos à integridade física e mental dos próprios estudantes, de seus colegas, amigos, familiares ou mesmo de estranhos.

Além disso, Rorty (1997) espera que os professores responsáveis pelo processo de socialização nas escolas incentivem seus alunos a lerem narrativas históricas e literárias a fim de adquirirem uma "imagem de si mesmos como herdeiros de uma tradição em prol da ampliação de liberdade e da ascensão da esperança" (RORTY, 2000a, p. 121). Ele escreve:

Ao atualizarmos Dewey um pouco, podemos imaginá-lo como alguém que queria que as crianças viessem a pensar delas próprias como cidadãs orgulhosas e leais de um país que, lenta e dolorosamente, livrou-se do jugo estrangeiro, libertou seus escravos, concedeu às suas mulheres o direito ao voto, conteve magnatas ladrões e licenciou seus sindicatos, liberalizou suas práticas religiosas, ampliou sua tolerância moral e religiosa e construiu instituições de ensino superior em que cinqüenta por cento de sua população poderia se inscrever - um país que contou entre seus cidadãos com Jefferson, Thoreau, Susan B. 
Anthony, Eugene Debs, Woodrow Wilson, Walter Reuther, Franklin Delano Roosevelt, Rosa Parks e James Baldwin. Dewey queria a inculcação dessa narrativa de liberdade e esperança fosse o núcleo do processo de socialização (RORTY, 2000a, p. 121-122).

Segundo Rorty (2000a), o processo complementar de autoindividualização e autocriação de um ser humano implica em uma posterior revolta contra o mesmo processo de socialização ao qual havia sido submetido. Desta maneira, a tarefa dos professores (universitários, na maioria das vezes) é apresentar aos seus alunos visões alternativas e discordantes daquilo que fora assumido consensualmente, isto é, tanto o conhecimento convencional das matérias disciplinares quanto os valores e normas morais e políticos da sociedade. Em termos deweyanos, Rorty (2000a) diz que por meio do contraste propiciado não por "critérios", mas por "narrativas inspiradoras e utopias obscuras", poder-se-ia "remover as barreiras que a socialização inevitavelmente impõe" (RORTY, 2000a, p. 120). Ele escreve:

A questão da educação superior não-profissionalizante é [...] ajudar os estudantes a perceberem que eles podem moldar a si próprios, que eles podem retrabalhar a auto-imagem infligida a eles pelo seu passado, a auto-imagem que fez deles cidadãos competentes, transformando-a em uma nova auto-imagem, uma que eles próprios ajudaram a criar (RORTY, 2000a, p. 118).

Neste sentido, Rorty afirma que para manter tais opiniões ele deve assumir o débito para com as ideias de John Dewey e, assim, reconhecerse "como um seguidor bastante fiel" dele (RORTY, 2000a, p. 118). O neopragmatista continua:

A grande contribuição de Dewey para a teoria educacional foi ajudar a nos livrar da idéia que a educação é uma questão de induzir à verdade ou deduzir a verdade. A educação primária e secundária sempre será uma questão de familiarizar o jovem com aquilo que os mais velhos consideram verdadeiro, seja isto verdadeiro ou não. Não é, e nunca será, função da educação básica desafiar o consenso 
prevalecente sobre o que é verdadeiro. A socialização tem de vir antes da individualização e a educação para a liberdade não pode ser iniciada antes de alguns constrangimentos terem sido impostos. Todavia, por razões bem diferentes, a educação superior não-profissionalizante também não é uma questão de inculcar ou induzir à verdade. Ela é, em vez disso, uma questão de incitar dúvidas e estimular a imaginação, portanto, de desafiar o consenso predominante. Se a educação pré-universitária produz cidadãos alfabetizados e a educação superior produz indivíduos autocriados, então as questões sobre se a verdade está sendo ensinada aos estudantes pode ser saudavelmente negligenciada (RORTY, 2000a, p. 118).

Assim, os professores do ensino superior devem oferecer cursos que combinem "treinamento vocacional especializado e provocação para a autocriação" (RORTY, 2000a, p. 123). Dentre estas provocações oferecidas pelos professores, mereciam destaque aquelas que fossem consideradas socialmente mais relevantes, no sentido de tornar vívidos tantos os êxitos quantos os fracassos do País ao nos consideramos cidadão leais.

Embora Rorty (2000a) localize os processos complementares de socialização e individualização em âmbitos escolares distintos, a saber - no ensino fundamental e médio, por um lado, e no ensino superior, por outro - ele não deixa de reconhecer que esta demarcação não é rigorosamente fixa, visto que, em ambos os casos, pode ocorrer situações nas quais os professores responsáveis pelos respectivos processos excedam a tarefa que é supostamente tomada como regra. Estas exceções podem ocorrer, por exemplo, a partir de uma opção dos professores que, sensibilizados pela curiosidade, dificuldade ou reivindicação de seus alunos, resolvem indicar a eles onde encontrar formas de pensar alternativas ao senso comum. Igualmente, as exceções também podem originar-se em virtude da condição estrutural do ensino no próprio país dos referidos professores, por questões administrativas peculiares de sua escola ou faculdade, ou ainda pela percepção de que a socialização necessária não foi suficientemente desenvolvida e que, portanto, antes da individualização, tal tarefa precisa ser completada ainda que seja no ensino superior.

A respeito disso, Rorty afirma que nas democracias liberais contemporâneas, a tensão entre as atitudes de políticos conservadores 
e radicais a respeito de educação e ensino "foi resolvida através de um compromisso bastante simples e satisfatório", ou seja, enquanto a "direita mantém o controle quase completo da educação primária e secundária e a esquerda tem gradualmente conseguido o controle da educação superior não-profissionalizante" (RORTY, 2000a, p. 116). Entretanto, Rorty (2000a) também considera que ambos os lados erram ao pensarem na educação como um processo contínuo e, por conseguinte, é desta concepção equivocada que se originam suas respectivas dificuldades em aceitar a importância e a complementaridade dos dois distintos aspectos da educação: a socialização e a individualização.

Ainda sobre o processo de individualização e autocriação, a perspectiva rortyana exara que a função social das faculdades e universidades é ajudar os estudantes a compreenderem que, ao compararmos nossa sociedade atual com sua versão pretérita e verificarmos o inegável progresso de uma em relação à outra, devemos nos precaver contra o comodismo generalizado que imobiliza nossos pensamentos e ações. Em outras palavras, as gerações vindouras devem atentar para o fato que, a despeito dos avanços nas nossas ideias, comportamentos, instituições, leis e relações sociais, a distância entre o que podia ter sido feito e o que foi efetivamente realizado é inimaginavelmente abissal. Assim, devemos nutrir a esperança de poder fazer com que toda nova geração de estudantes esquive-se do conformismo e passe a perceber e a combater tudo aquilo que venha a ser considerado inútil, vil e destituído de liberdade que subrepticiamente se alastra na sociedade.

Com sorte, os melhores deles serão bem-sucedidos na alteração da sabedoria convencional, de tal forma que a próxima geração seja socializada de um modo diferente daquele em que eles próprios foram socializados. Esperar que esse modo seja um pouco diferente é esperar que a sociedade permaneça reformista e democrática, em vez de convulsionada pela revolução. Esperar, que ela seja perceptivelmente diferente é, apesar de tudo, lembrar que o crescimento é certamente o único fim a que a educação superior pode servir e também lembrar que a direção do crescimento é imprevisível (RORTY, 2000a, p. 124-125). 
Assim, para Rorty, é importante lembrar que no ensino superior não profissionalizante antes de qualquer tentativa de fixar um conteúdo, devemos priorizar a tanto a liberdade de cátedra quanto a liberdade de ensino, visto que sem elas o processo crítico de individualização fica comprometido, isso porque, antes de tudo, o início deste processo se dá mediante o próprio ato de desempenhar a liberdade, praticado por professores e alunos. Tais exercícios de liberdade são verificados, principalmente, nas ocasiões em que os relacionamentos entre alunos e professores são norteados por um viés socrático, isto é, de amor à sabedoria, em contraposição ao sentido platônico, de amor à verdade. Os alunos podem travar tais ocasiões de relacionamentos de duas maneiras: com os seus professores vivos que ministram aulas e orientam e com os professores mortos que se fazem notar por meio do legado de suas obras. Ele continua:

Em ambos os casos, o entusiasmo recíproco entre o professor e o estudante, conecta-os em um relacionamento que tem pouco a fazer com a socialização, mas muito a fazer com a autocriação, e é o principal meio através do qual as instituições de uma sociedade liberal conseguem ser transformadas. A menos que tais relacionamentos sejam constituídos, os estudantes nunca perceberão qual é o propósito das instituições democráticas: a saber, tornar possível a invenção de novas formas de liberdade humana, admitindo liberdades, nunca antes consideradas (RORTY, 2000a, p. 126).

O filósofo neopragmatista também aborda os referidos processos de socialização e, principalmente, individualização, em termos relativamente diferentes, ao discorrer em breves teses sobre algumas das facetas do novo intelectual, por ele denominado de intelectual humanista. Na terceira tese, por exemplo, ele sustenta que a "função real dos intelectuais humanistas é instilar dúvidas nos estudantes sobre as suas próprias auto-imagens e sobre a sociedade à qual pertencem (RORTY, 2000b, p. 127). As pessoas que Rorty descreve como intelectuais humanistas - ele próprio incluso nesta definição - são os professores que contribuem para tentar assegurar que cada nova geração estudantes possua uma consciência moral ligeiramente diferente da geração precedente. Esta mudança no aspecto moral das 
gerações vindouras em relação às precedentes deve levar em consideração que o material utilizado para tal função, as listas de leitura, devem ser planejadas a fim de preservar um tênue equilíbrio entre dois tipos de necessidade:

A primeira é a necessidade dos estudantes terem pontos de referência comuns com as pessoas das gerações prévias e de outras classes sociais - de tal maneira que os avós e netos, as pessoas [...] terão de ler muito dos mesmos livros. A segunda é a necessidade dos professores serem capazes de ensinar preferencialmente os livros que os motivaram, que os excitaram, que mudaram suas vidas, do que ter de ensinar um plano de curso transmitido por um comitê (RORTY, 2000b, p. 130).

A consecução de tal proposta ocorreria de uma maneira não exatamente tranquila, visto que, por um lado, a liberdade acadêmica nem sempre pode vicejar nas cercanias onde predomina a sombra espectral de sua contraparte, a burocracia universitária. Por outro lado, como os professores discordam consideravelmente sobre seus cânones e heróis, os estudantes podem não aproveitar devidamente boa parte dos cursos em virtude da sobrecarga de leitura. Diante desse impasse e em conformidade com os preceitos neopragmatistas, a sugestão rortyana consiste na ideia de que devemos manter as ciências humanas em constante e rápida mudança a fim de que continuem caracteristicamente indefiníveis e estrategicamente não administráveis.

\section{Considerações finais}

Para Rorty, a solidariedade humana não deve ser concebida como um fato a ser descoberto, mas sim como um objetivo a atingir. A realização desse projeto passaria, necessariamente, pela ação da imaginação: isto porque as dores e humilhações afetam todos os seres humanos e a nossa capacidade imaginativa permite que ampliemos a nossa sensibilidade ao sofrimento alheio. Assim, por meio desta experiência redescritiva, é possível criar a solidariedade em que antes havia apenas a indiferença gerada por uma rígida distinção ente o nós e o eles. 
Na filosofia da educação de Rorty este processo de redescrição - de nós mesmos, da outras pessoas e do mundo - é retomado quando ele avalia a educação como uma combinação entre dois processos contínuos e complementares: os processos educacionais de socialização e individualização. No primeiro caso, as pessoas recebem valores (normas de comportamento, regras e leis) que as ajudarão no relacionamento cotidiano com as pessoas de seu grupo social; no segundo caso, as pessoas tomam conhecimento de perspectivas alternativas que criticam os valores assimilados e, em alguns casos, apresentam valores novos. Este processo de crítica e posterior redescrição dos indivíduos pode ser iniciado tanto por intermédio dos ensinamentos de um professor quanto por narrativas envolventes relatadas em romances, filmes, histórias em quadrinhos e demais áreas nas quais predomine a narrativa.

Assim, embora a proposta rortyana soe, em alguns momentos, bastante vaga - ele próprio reconhece ser uma utopia - lembramos que as grandes ideias, os sonhos e as esperanças compartilham dessa condição, visto que elas nunca se apresentam aos corações e mentes humanos de forma definida e acabada.

\section{Referências}

ARCILLA, R. V. Edificação, conversação e narrativa: os motivos rortianos para a filosofia da educação. Filosofia, sociedade e educação, Marília, v.1, n.1, p. 47-58, jul./dez. 1997.

GARRISON, J.; NEIMAN, A. Pragmatism and Education. In: BLAKE, N.; SMEYERS, P. ; SMITH, R.; STANDISH, P. (Ed.). The Blackwell Guide to the Philosophy of Education. Oxford: Blackwell, 2003. p. 21-37. RORTY, R. Philosophy and the mirror of nature. Oxford: Blackwell, 1979. . Contingency, irony and solidarity. Cambridge: Cambridge University Press, 1989.

. Objectivity, relativism, and truth: philosophical papers volume I. Cambridge: Cambridge University Press, 1991.

. Os perigos da sobre-filosoficação. Filosofia, sociedade e educação, Marília, v.1, n.1, p. 59-67, jul./dez. 1997. 
. Education as socialization and individualization. In:

Philosophy and Social Hope. London: Penguin, 2000a. p. 114-126.

. The Humanistic Intellectual: Eleven Theses. In:

Philosophy and Social Hope. London: Penguin, 2000b. p. 127-130.

. Duas profecias. Folha de S. Paulo, São Paulo, 24 maio 1998.

Caderno Mais!, p. 7.

. Philosophy as cultural politics: philosophical papers volume IV.

Cambridge: Cambridge University Press, 2007.

Data de registro: $18 / 02 / 2011$

Data de aceite: 18/05/2011 